\title{
INTERPRETAÇÃO FENOLÓGICA DE CINCO ESPÉCIES DE CHRYSOBALANACEAE NA RESERVA FLORESTAL ADOLPHO DUCKE, MANAUS, AMAZONAS, BRASIL.
}

\author{
Jorge Elias Alván RUIZ1', Jurandyr da Cruz ALENCAR ${ }^{2}$
}

\begin{abstract}
RESUMO - Este estudo foi desenvolvido na Reserva Florestal Adolpho Ducke, ao norte de Manaus. Analisaram-se dados de observações fenológicas sobre cinco espécies da família Chrysobalanaceae, Licania heteromorpha L. longistyla L. octandra Couepia longipendula, C. robusta e dados meteorológicos obtidos no periodo de 1970 a 1994. Determinaram-se as percentagens médias mensais de ocorrência, freqüência, regularidade, data e duração média anual das fenofases, e o índice de sincronia entre indivíduos e na população para a plena floração $\left(\mathrm{F}_{2}\right)$, frutos maduros $\left(\mathrm{F}_{5}\right)$ e folhas novas $\left(\mathrm{F}_{8}\right)$ de cada espécie, $L$. heteromorpha apresentou pico máximo de plena floração na transição para a estação chuvosa (Nov.- Jan.); L. longistyla (Jun.) e L. octandra (Jul.) na transição para a estação seca; $C$. longipendula e C. robusta na estação seca (Out.). As espécies apresentaram freqüência anual a supra-anual na floração, com padrão irregular, com exceção de $L$. octandra supra-anual e padrão muito irregular. A duração média da floração foi de 4,8 meses e de 5,5 meses para a frutificação para as cinco espécies. $O$ índice de sincronia da plena floração foi alta para $L$. octandra $(0,79)$, média para C. longipendula $(0,56)$ e baixa para $L$. heteromorpha, L. longistyla e C. robusta $(<0,32)$ espécies mostraram ser perenifólias. Uma análise multivariada mostrou que a plena floração teve correlação linear negativa com a precipitação e umidade relativa $(r=-0,34)$ e correlação positiva com a insolação $(r=0,29)$, temperatura máxima $(r=0,26)$ e evaporação $(r=$ $0,31)$; a fase de frutos maduros apresentou correlação positiva com a precipitação $(r=0,27)$ e negativa com a temperatura minima $(r=-0,35)$ e insolação $(r=-0,27)$; a fase de folhas novas apresentou correlação semelhante à da plena floração.
\end{abstract}

Palavras chaves: Fenologia, sincronia, clima, floresta tropical úmida.

\section{Phenological Interpretation of Five Chrysobalanaceae Tree Species in the Adolpho Ducke Forest Reserve, Manaus, Amazonas, Brazil.}

ABSTRACT - This study was carried out in the Adolpho Ducke Forest Reserve,on north of Manaus. Phenological observations on five species of Chrysobalanaceae, Licania heteromorpha, $L$. longistyla, $L$. octandra, Couepia longipendula and C. robusta were analyzed in relation to meteorological data over 25 years. The monthly mean percentages of occurrence, frequency, regularity, date, duration of the phenophases, and the synchrony among individuals and in the population for flowering $\left(\mathrm{F}_{2}\right)$, mature fruits $\left(\mathrm{F}_{5}\right)$ and new leaves $\left(\mathrm{F}_{8}\right)$, were calculated. $L$. heteromorpha showed maximum flowering in the transition to the wet season (Nov.-Jan.); L. longistyla (June) and L. octandra (July) in the transition to the dry season (MayJuly); C. longipendula and C. robusta in the dry season (Oct.). The species showed annual to supra annual frequency of phenophase occurrence and an irregular flowering pattern, except for $L$. octandra supra annual and very irregular pattern. The mean duration of the flowering (all species) was 4.8 months and 5.5 months for the fruiting. The synchronism index of flowering in the population was high in L. octandra (0.79), medium in C. longipendula $(0.56)$ and low in L. heteromorpha, L. longistyla and C. nobusta $(<0.32)$. All the species showed characteristics of evergreen plants. A principal components analysis of three phenological phases $\left(\mathrm{F}_{2}, \mathrm{~F}_{5} \mathrm{~F}_{8}\right)$ and meteorological variables showed that flowering $\left(\mathrm{F}_{2}\right)$ had a negative linear correlation with rainfall and relative humidity $(r=-0.34)$, and a positive correlation with insolation $(r=$ $0.29)$, maximum temperature $(r=0.26)$ and evaporation $(r=0.31)$; mature fruits $\left(F_{5}\right)$ showed a positive correlation with rainfall $(r=0.27)$ and a negative correlation with minimum temperature $(r=-0.35)$ and insolation $(r=-0,27)$; the new leaves phase $\left(F_{8}\right)$ had correlations similar to those found for flowering $\left(F_{2}\right)$. Key-words: Phenology, synchrony, climate, tropical rain forest.

1 Eng $^{\mathrm{o}}$ Florestal, M.Sc., Pesquisador. Av, Abelardo Quiñonez, km 2,5, Apartado 784, Iquitos, Peru.

2 Eng $^{0}$ Florestal, Prof. Dr., Pesquisador. Caixa Postal 478, 69011-970 Manaus, AM, Brasil. 


\section{INTRODUÇÃO}

A recuperação de florestas exploradas é difícil porque não há fornecimento adequado de sementes e inexistem informações sobre a fenologia das espécies para orientar a coleção de sementes (Magalhães \& Alencar, 1979). Romero \& Romero (1983) recomendaram observações fenológicas durante um periodo minimo de cinco anos. A falta de informação fenológica dificulta outros estudos sobre a biologia das espécies e a determinação da época para coleta de sementes (Umaña \& Alencar, 1993).

Araújo (1970) e Alencar et al. (1979) determinaram que em algumas espécies a floração e frutificação repetem-se ano a ano, bianualmente ou em intervalos de alguns anos, obedecendo às variações climáticas. Araújo (1970) e Alencar et al. (1979) relataram que os períodos de floração $\mathrm{e}$ frutificação ocorreram, para a maioria das espécies na Reserva Ducke, na dependência da distribuição das chuvas, com dominância da floração na estação seca e maior incidência de frutos maduros no período chuvoso.

Alencar et al. (1979) determinaram que $63 \%$ de 27 espécies estudadas na Reseva Ducke floresceram durante a estação seca. Alencar (1988) determinou que a floração de Copaifera multijuga Hayne teve maior ocorrência entre janeiro e abril (estação chuvosa) e a frutificação com maior freqüência entre maio e agosto (transição para a seca), comportamento que difere da maioria das espécies arbóreas já estudadas na Amazônia Central.

A floração e frutificação são claramente sazonais nas florestas da
Guiana, com o pico de floração entre setembro e novembro, na estação seca (Steege \& Persaud, 1991), coincidindo com o pico de floração na floresta da Guiana Francesa (Sabatier,1985). A frutificação no Suriname teve forte relação com a precipitação, e segundo eles as Chrysobalanaceae apresentaram boa floração nos meses de maio, julho e dezembro na floresta tropical da Guiana.

Alencar et al. (1979) encontraram que a queda de folhas de 27 espécies ocorreu durante todo o ano na Reseva Ducke, mas a maior quantidade de folhas foi perdida na estação seca, e as espécies comportaram-se como perenifólias (59,25\%), em maioria. Miranda (1991) relatou que o periodo de brotamento das árvores de Alter-do-Chão (Pará) também ocorreu logo após a queda das folhas e os eventos fenológicos apresentaram flutuações sazonais, sendo melhor evidenciados nas fases de queda de folhas. A senescência das folhas parece ser mais claramente induzida pelo estresse' da seca do que pelo comprimento do dia (Daubenmire, 1972).

Alvim (1962), no Peru, em região temperada, determinou que os fatores diretos principais para estimular a floração são a radiação solar e a longitude do dia e como secundários a temperatura e água do solo. As espécies de regiões tropicais mostram oscilações periódicas de crescimento e de floração, mas há muita dúvida sobre os fatores que controlam esta periodicidade (Alvim, 1964). Até agora não foram feitos estudos que permitem separar a genética e os componentes ambientais da variação no tempo de floração (Jackson, 1966; Primack, 1980). A maioria das espécies com sementes 
grandes, disseminadas ou dispersadas por animais, amadureceram no final da estação seca e no início da estação chuvosa nas florestas tropicais sazonais do Panamá e Costa Rica (Smithe, 1970). A floração e renovação de folhas de algumas espécies podem também ser inibidas por períodos secos prolongados ou por períodos relativamente longos de excessiva umidade, podendo-se considerar-se isto como uma manifestação de hidroperiodismo (Longman \& Jenik, 1974).

Alencar \& Araújo (1980) mostraram que a luz, a temperatura e a água são os fatores ambientais relevantes num ecossistema terrestre. Borchert (1994), numa floresta seca da Costa Rica, determinou que a variação sazonal e conteúdo de água nas espécies florestais são, aparentemente, os principais determinantes da fenologia e distribuição das espécies arbóreas.

Para Borchert (1983) os ritmos sazonais de crescimento e reprodução das árvores tropicais são determinados por fatores genéticos e ambientais. Em quase todos os ambientes tropicais existe uma variação sazonal de temperatura, umidade, pluviosidade, velocidade do vento e comprimento do dia, mas a amplitude dessa variação é pequena (Richards, 1952 apud Miranda, 1991). Longman \& Jenik (1974) e Reich \& Borchert (1984) mencionaram que nas regiões próximas ao Equador as variações de temperatura e fotoperiodo são mínimas e, considerando as grandes variações pluviométricas, parece improvável que a temperatura e o fotoperiodo afetem significantemente $o$ desenvolvimento das árvores tropicais.

Os objetivos deste trabalho foram avaliar o comportamento fenológico de cinco espécies de árvores da familia Chrysobalanaceae; verificar os indices de sincronia das três fenofases principais, a duração da floração e frutificação, a regularidade da floração; e determinar a correlação destas fenofases com sete variáveis meteorológicas.

\section{MATERIAL E MÉTODOS}

\section{Área de estudo}

Os estudos foram feitos na Reserva Florestal Adolfo Ducke, situada $26 \mathrm{~km}$ ao norte de Manaus, em floresta tropical úmida de terra-firme, com área de 10.072 hectares, compreendida entre as coordenadas $59^{\circ} 52^{\prime} 40^{\prime \prime}$ e $59^{\circ} 52^{\prime} 00^{\prime \prime}$ de longitude Oeste, e entre $03^{\circ} 00^{\prime} 00^{\prime \prime}$ e $03^{\circ} 08^{\prime} 00^{\prime \prime}$ de latitude Sul (Ribeiro,1976).

O clima desta área é do tipo $A f i$, de acordo com a classificação de Köppen: $A$ - Clima tropical praticamente sem inverno, a temperatura média do mês mais frio nunca é inferior a $18^{\circ} \mathrm{C} ; f$ - chuvas durante todo o ano; $i$ - indica isotermia, ou seja, as oscilações anuais de temperatura média não chegam a $5^{\circ} \mathrm{C}$ (Ribeiro, 1976). O solo predominante na área do estudo é o Latossolo Amarelo distrófico (Umaña \& Alencar, 1993). Segundo Ranzani (1979), este tipo de solo possui horizonte $A$ Ócrico e horizonte $B$ Óxico em perfil profundo, de baixa fertilidade natural e baixa saturação em bases; são solos ácidos, 
com boa drenagem e resistentes à erosão. Rodriguez (1995) relatou que a saturação de aluminio é elevada (acima de $50 \%$ ), conferindo aos solos o caráter álico.

\section{Material}

Foram analisados dados fenológicos de cinco espécies de Chrysobalanaceae: Licania heteromorpha Bentham var. heteromorpha. Exicata: $55.359 ; 57.835 ; 57.838$; Licania longistyla Fritsch: $55.239 ;$ 55.439; 57.842; 57.896; Licania octandra Prance var. pallida: 57.839; 57.892; 57.893; 57.894; 57.895; Couepia longipendula Pilger: 54.751; 54.841; 55.243; 57.840; 57.897; e Couepia robusta Huber: 57.834; 55.381; 55.750; $57.862 ; 57.833$ (as excicatas são da Reserva Ducke e as espécies foram identificadas no Herbário do INPA). Na seleção das árvores e espécies foram consideradas as suas ótimas caracteristicas fenotípicas (Araújo, 1970; Alencar et al., 1979). Os dados das variáveis meteorológicas foram obtidos na Estação Meteorológica da Reserva Ducke e cedidos pela Coordenação de Pesquisas em Geociências (CPGC/ INPA).

\section{Métodos}

Foram analisados dados de floração, frutificação e mudança foliar, durante o período de janeiro de 1970 a dezembro de 1994. As observações foram feitas mensalmente, com o auxílio de um binóculo, seguindo-se as fenofases utilizadas por Araújo (1970): Floração (botões florais $=\mathrm{F}_{1}$; plena floração $=\mathrm{F}_{2}$; floração terminando ou terminada $=\mathrm{F}_{3}$ ); Frutificação (frutos novos $=\mathrm{F}_{4}$; frutos maduros $=\mathrm{F}_{5}$; frutos maduros caindo $\mathrm{e}$ sementes dispersadas $=\mathrm{F}_{6}$ ); e Mudança foliar (árvores com pouca folha ou desfolhada $=\mathrm{F}_{7}$; folhas novas $=\mathrm{F}_{8}$; folhas novas em maioria $=\mathrm{F}_{9}$; folhas velhas $=$ $F_{10}$ ). Os dados foram calculados pelo Programa Fenolog, desenvolvido pela CPST/INPA sob a supervisão do $2^{\circ}$ autor, em linguagem DBASEIII, o qual encontra-se disponivel na CPST. Por meio deste programa foram calculadas as porcentagens médias de ocorrências mensais, os indices de sincronia, a duração média mensal e as ocorrências por fenofase para cada ano.

Os padrões de floração foram descritos segundo Newstrom et al. (1994 a; b):

Freqüência, baseada no número de ciclos por ano com ou sem fenofases: contínua, quando houver sempre floração mas podendo ter curtas lacunas; sub-anual, quando houver fases múltiplas de floração irregular por ano; anual, quando ocorrer uma fase maior de floração por ano; supra-anual, quando ocorrer ciclos de floração (intervalos de 3, 4 ou mais anos); subclasses: alternada e rara.

Regularidade, dada pela variação em comprimento das fases de floração e intervalos de não floração, com duas subclasses: regular, quando ocorrem durações similares de fases e ciclos; irregular, quando ocorrem durações variáveis de fases e ciclos.

Duração, avaliada pela amplitude de tempo (meses) em cada ciclo ou fenofase, com subclasses: breve ( 1 mês), intermediária (1 a 5 meses) e prolongada ( 5 meses).

Data, mês ou estação do ano na qual ocorre a fenofase. 
Sincronia, é a ocorrência simultânea de um evento particular.

$O$ Índice de Sincronia foi calculado de acordo com Augspurger (1983):

$$
X_{i}=(1 / n-1)\left(1 / f_{i}\right) \sum_{j=1}^{n} e_{j}^{j \neq i}
$$

Onde: $\mathrm{e}_{\mathrm{j}}=$ número de meses em que ambos individuos ou espécies $\mathrm{i}$ e $\mathrm{j}$ estâo florescendo sincronicamente, $\mathrm{j} \neq \mathrm{i} ; \mathrm{f}_{\mathrm{i}}=$ número de meses do indivíduo ou espécie $\mathrm{i}$ em floração; $\mathrm{n}=$ número de individuos na população. Quando $X=1$ ocorre sincronia perfeita, ou seja, todos os meses de floração do indivíduo i coincidem com todos os meses de floração dos outros indivíduos na população $\mathrm{j} \neq \mathrm{i}$. Quando $\mathrm{X}=0$ não ocorre sincronia, indicando que não existe sobreposição entre qualquer mês da floração do indivíduo i com qualquer outro indivíduo na população $\mathrm{j} \neq \mathrm{i}$.

A Sincronia da população foi calculada por:

$$
\mathrm{Z}=1 / \mathrm{n} \sum_{\mathrm{j}=1}^{\mathrm{n}} \mathrm{X}_{\mathrm{i}}
$$

Onde: $X_{i}$ é a sincronia do indivíduo i com seus coespecíficos.

$\mathrm{O}$ índice de sincronia é mais importante para a fase de floração, para entender o processo de reprodução da espécie. Entretanto, no presente trabalho foram calculados os indices para as fases de frutos maduros e folhas novas, para auxiliar a compreensão da fenologia das espécies. Os valores de sincronia entre indivíduos e espécies foram testados pela análise não paramétrica de Kruskal-Wallis (Campos, 1979).

As relações entre as variáveis fenológicas (plena floração; frutos maduros e folhas novas), por serem estas as mais representativas, e as variáveis meteorológicas (precipitação em mm, insolação em horas, umidade relativa do ar em \%, temperatura média, temperatura máxima e minima absolutas em ${ }^{\circ} \mathrm{C}$ e evaporação liquida $\mathrm{em} \mathrm{mm}$ ), foram avaliadas por meio de análise multivariada dos componentes principais, considerando os valores médios mensais das variáveis (Bouroche \& Saporta, 1980; Callegari-Jacques, 1991; Philippeau, 1992; Alencar, 1990, 1994; Rodriguez, 1995). Esta análise fornece uma matriz de correlações lineares entre as variáveis e a representação plana das relações nos eixos, a qual mostra a oposição ou não entre as variáveis.

Foi registrada a forma e posição da copa das árvores, para cada espécie, classificadas de acordo com Shield, (1965), apud Alencar et al. (1979), para analisar principalmente a posição que cada árvore ocupa na estrutura da floresta (emergente, dossel, dossel, inferior).

\section{RESULTADOS E DISCUSSÃO}

\section{Clima}

Observou-se que a precipitação média anual para os anos de 1970 a 1994 foi de $2.425,9 \mathrm{~mm}$; a temperatura média anual foi de $25,7^{\circ} \mathrm{C}$, temperatura máxima mensal foi de $32,3{ }^{\circ} \mathrm{C}$ e temperatura minima mensal foi de $21,8^{\circ} \mathrm{C}$ (entre junho e julho). Os meses que apresentaram as maiores médias de temperatura máxima (entre $33,2^{\circ} \mathrm{C}$ e $33,8^{\circ} \mathrm{C}$ ) foram setembro, outubro e novembro, que caracterizam a estação seca, que vai de agosto a outubro; a estação chuvosa vai de novembro a maio; junho e julho são meses de transição para 
a estação seca. Os maiores valores de insolação e evaporação ocorreram entre julho e outubro (estação seca), com picos em agosto ( $>200$ horas e $<100 \mathrm{~mm}$ ), respectivamente. A umidade relativa apresentou maiores valores entre dezembro a maio, durante a estação chuvosa, sendo inferior nos outros meses, porém alta $(>87 \%)$ e inferior a $100 \%$ (Fig. 1). Alencar (1994) calculou para o período de 1970 a 1990 as seguintes médias mensais nessa mesma área de estudo: Umidade relativa $(87,26 \%)$, precipitação $(204,37 \mathrm{~mm})$, insolação (147,22 horas), evaporação $(63,67 \mathrm{~mm})$ e temperatura média $\left(25,6^{\circ} \mathrm{C}\right)$.

\section{Ocorrência média mensal das Fenofases}

Licania heteromorpha apresentou a plena floração na transição para a estação chuvosa, com maiores valores nos meses de dezembro e janeiro. A maior ocorrência de frutos maduros foi entre abril e junho, com pico em maio, ao final da estação chuvosa. A desfolhação foi nula durante todos os anos. As folhas novas apresentaram maiores valores na estação seca, com pico em agosto. As folhas velhas ocorreram durante 0 ano todo, caracterizando esta espécie como perenifólia. Apresenta forma de copa boa e a posição da copa está entre o dossel e o dossel inferior (Fig. 2).

Licania longistyla apresentou a plena floração na transição para a estação seca, com pico em junho. Ocorreram frutos maduros entre agosto e fevereiro, com picos em outubro e novembro, na transição da estação seca para a estação chuvosa. A desfolhação apresentou pico no mês de agosto, na estação seca. Ocorreram folhas novas com maiores valores na estação seca. As folhas velhas foram constantes durante o ano todo, caracterizando a espécie como perenifólia. Apresenta boa forma de copa e a posição das copas situase entre emergente e o dossel (Fig.3).

Licania octandra apresentou a plena floração com pico em julho, na

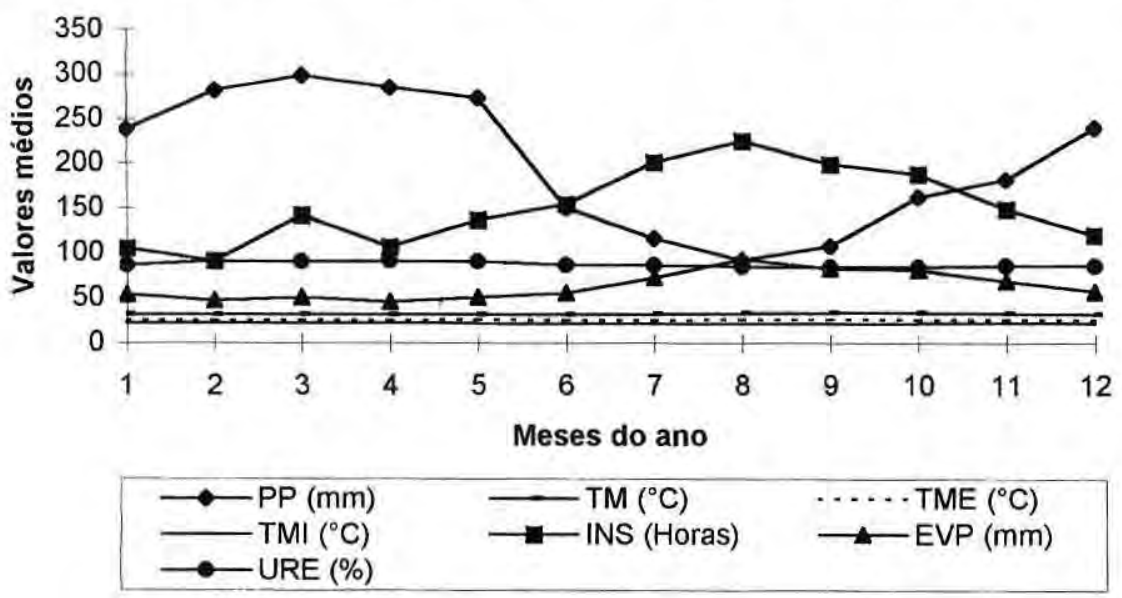

Figura 1. Valores médios mensais das variáveis meteorológicas na Reserva Ducke, Manaus, AM, de 1970 a 1994. PP (precipitação); TMI (temperatura minima); TM (temperatura máxima; TME (temperatura média); URE (umidade relativa); INS (insolação); EVP (evaporação). 


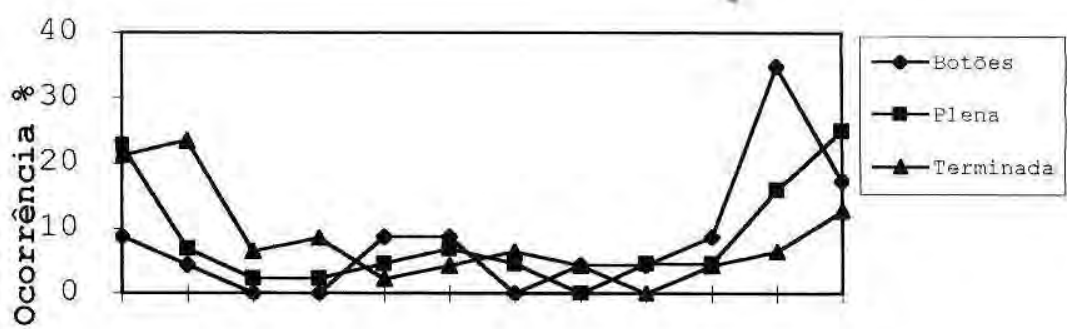

b)

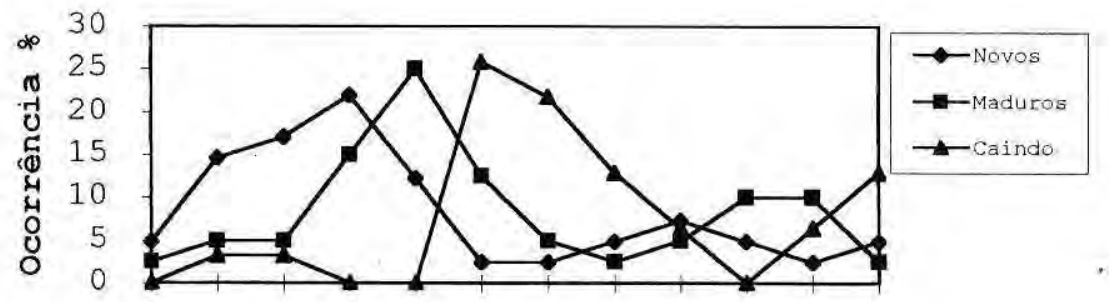

c)

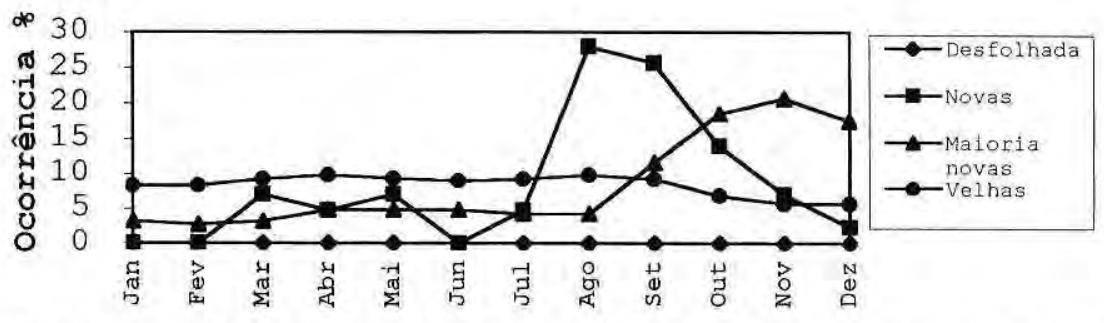

Figura 2. Floração (a), frutificação (b) e mudança foliar (c) de Licania heteromorpha Bentham var. heteromorpha. Reserva Ducke, Manaus, AM, de 1970 a 1994.

transição para a estação seca. Foram observados frutos maduros entre agosto e janeiro, com maior ocorrência em outubro, na estação seca. As folhàs novas ocorreram com maiores valores entre junho e outubro, com pico em setembro, na estação seca. As folhas velhas ocorreram durante $o$ ano todo, com valores mensais baixos $(<10 \%)$, sendo considerada como espécie perenifólia. Apresenta boa forma de copa e a posição da copa está entre emergente e o dossel (Fig. 4).

Conepia longipendula apresentou a plena floração com maiores valores entre setembro e novembro, na estação seca. A fase de frutos maduros apresentou picos em janeiro e fevereiro, na estação chuvosa. A desfolhação aconteceu numa única ocasião, em março de 1974, e por isso a espécie é considerada perenifölia. As folhas novas ocorreram durante todo o ano, com ocorrência máxima em junho, na transição para a estação seca, e em outubro, na estação seca. Pelo comportamento da fase de folhas velhas a espécie é perenifólia. A espécie apresenta copa tolerável e a posição da copa está concentrada mais no dossel 
a)

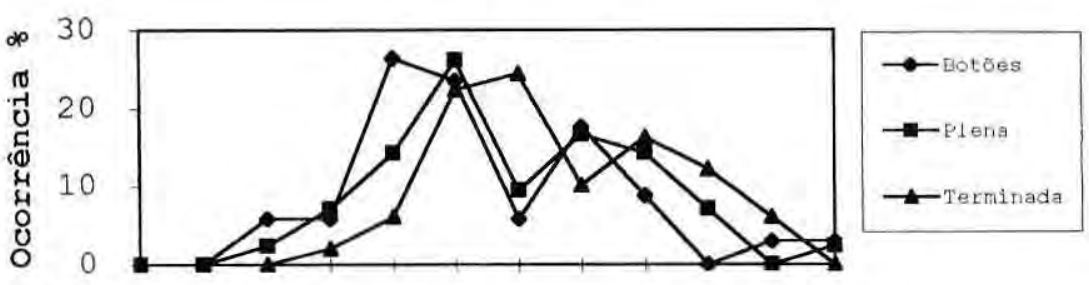

b)

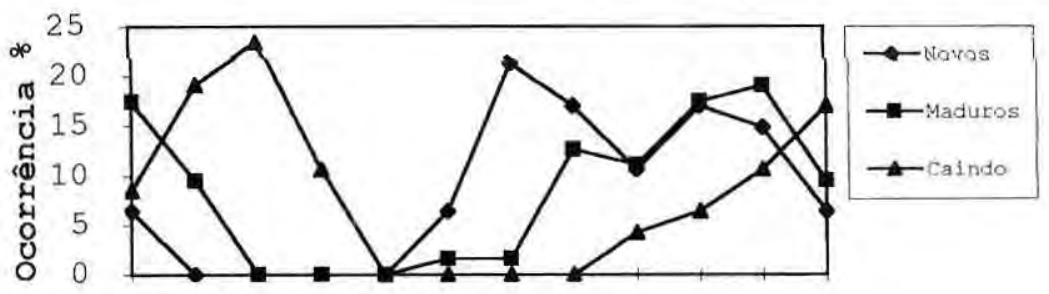

c)

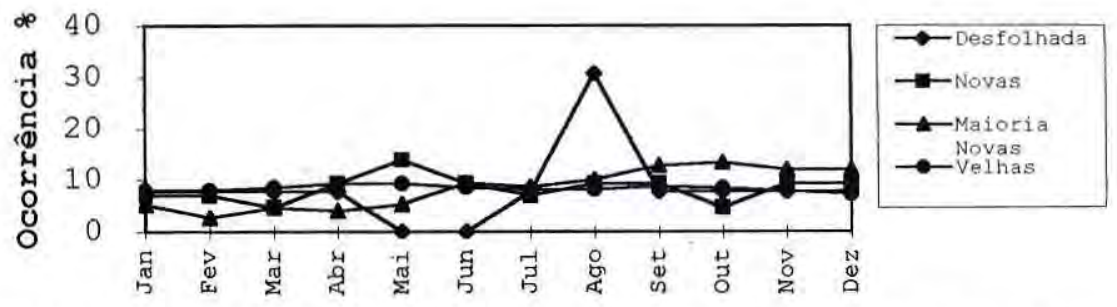

Figura 3. Floração (a), frutificação (b) e mudança foliar (c) de Licania longistyla Fritsch. Reserva Ducke, Manaus, AM, de 1970 a 1994.

do que no estrato emergente (Fig. 5).

Couepia robusta apresentou a plena floração entre agosto e fevereiro, com pico em outubro, na estação seca. Os frutos maduros ocorreram com maior freqüência entre janeiro e junho, sendo máxima em abril, na estação chuvosa. A desfolhação ocorreu entre abril e dezembro, com pico em junho, na transição para a estação seca. As folhas novas tiveram maiores ocorrências entre maio e agosto, com pico em julho, na transição para a estação seca.
A fase de folhas velhas ocorreu durante todo o ano, sendo a espécie considerada como perenifólia. Apresenta copa perfeita, na posição emergente (Fig. 6).

O pico da plena floração de $L$. longistyla e $L$. octandra ocorreu na transição para a estação seca (junho e julho); $C$. longipendula e $C$. robusta ocorreu na estação seca (outubro) e $L$. heteromorpha ocorreu na estação chuvosa (dezembro e janeiro).

Dada a inexistência de resultados 
a)

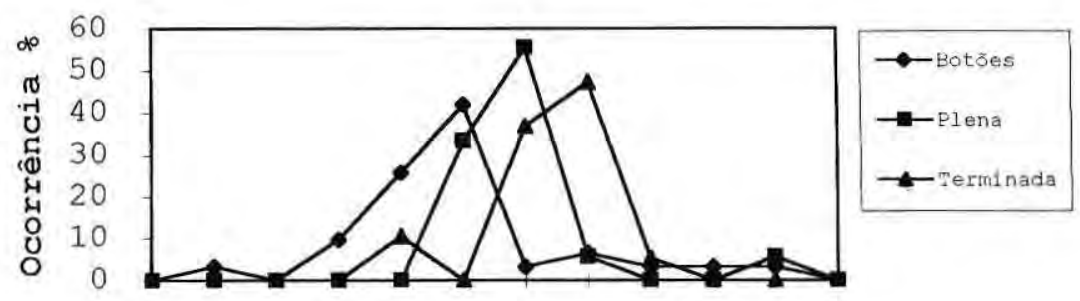

b)

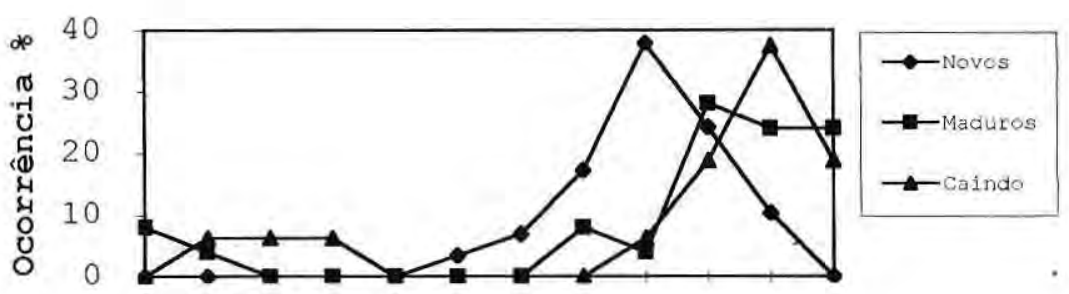

c)

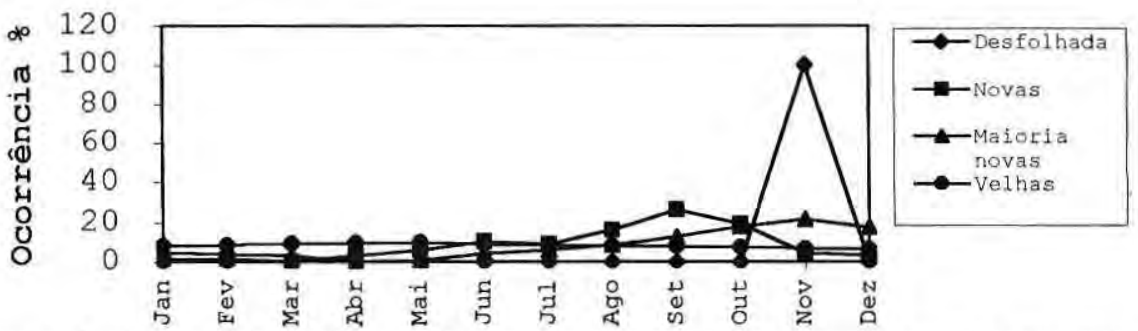

Figura 4. Floração (a), frutificação (b) e mudança foliar (c) de Licania octandra var. pallida Prance. Reserva Ducke, Manaus, AM, de 1970 a 1994.

fenológicos sobre estas espécies, citamse alguns resultados sobre, outras espécies desta familia: segundo Cavalcante (1988) Licania tomentosa floresceu entre julho e agosto (estação seca) com frutos maduros entre dezembro e janeiro (estação chuvosa), na região próxima a Belém-Pará. Falcão et al. (1981) determinaram que Couepia bracteosa Benth. floresceu no final da estação chuvosa, entre abril e julho, e a frutificação ocorreu entre junho e março, com mudança foliar entre março e abril, na estação chuvosa.

Vários autores já relataram que a floração, em árvores de floresta tropical, ocorreu principalmente durante a estação seca: Araújo (1970) e Alencar et al. (1979) na Reserva Ducke, Brasil; Alencar (1990) na Reserva Biológica de Campina, Manaus, AM, Brasil; Steege \& Persaud (1991 nas florestas da Guiana; Arostegui \& Diaz (1992) em Jenaro Herrera, Peru; Franciscon 
a)

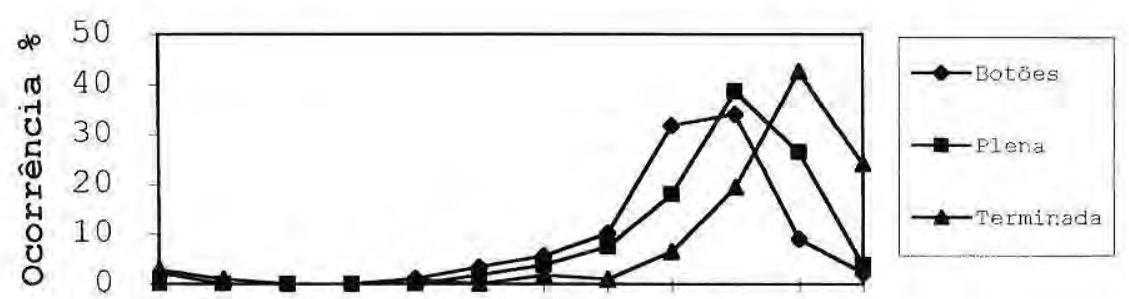

b)

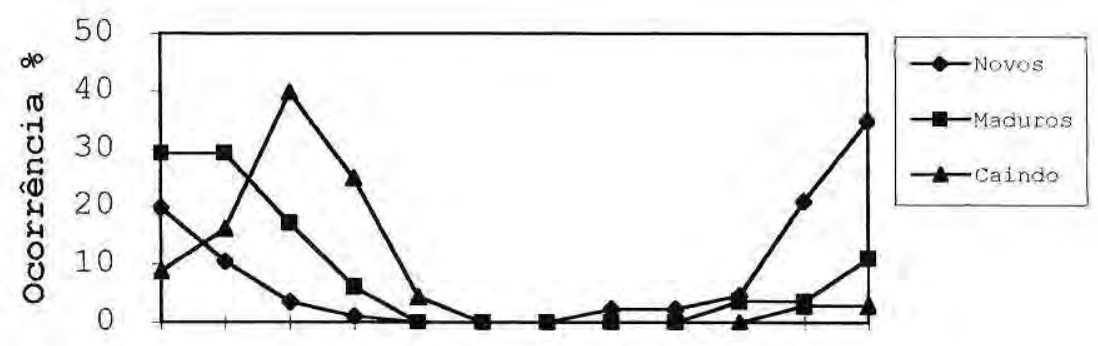

c)
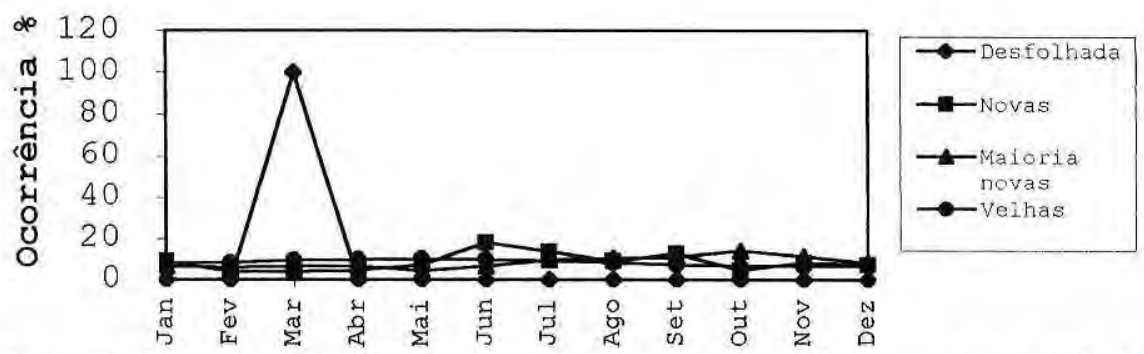

Figura 5. Floração (a), frutificação (b) e mudança foliar (c) de Couepia longipendula Pilger. Reserva Ducke, Manaus, AM, de 1970 a 1994.

(1993) na Reserva Ducke, Brasil.

Apenas Licania heteromorpha apresentou comportamento similar ao de Copaifera multijuga Hayne (Alencar, 1988) e de Vouacapoua pallidor Ducke, Dipteryx odorata Willd, Peltogyne paniculata Benth. subesp. paniculata (Alencar, 1991), as quais apresentaram maior floração na estação chuvosa.
Quanto à fase de frutos maduros, os picos ocorrreram na estação chuvosa para L. heteromorpha (maio), C. longipendula (janeiro e fevereiro), C. robusta (abril), como a maioria das espécies estudadas na Reserva Ducke (Araújo, 1970; Alencar et al. 1979) e coincidindo com os resultados de outros autores (Mori \& Prance, 1979; Falcão et al. 1981; Alencar, 1988; Steege 
a)

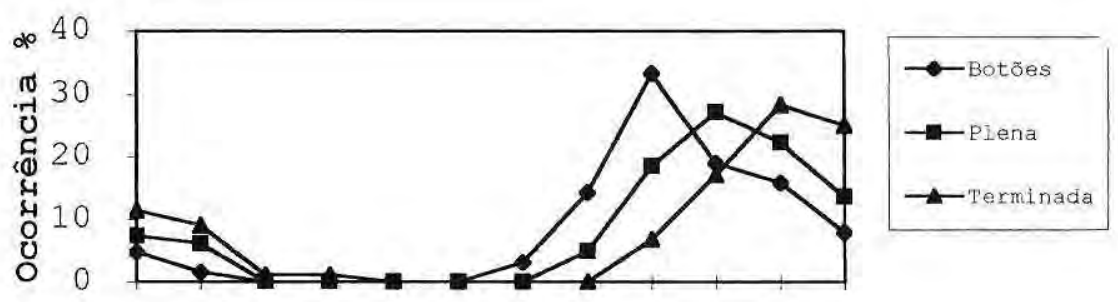

b)

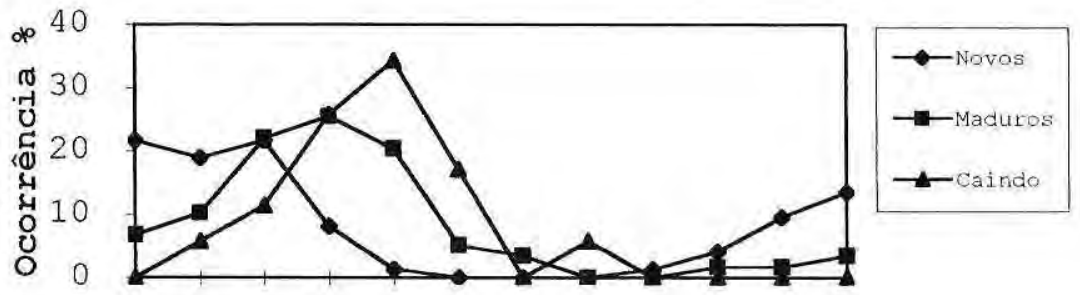

c)

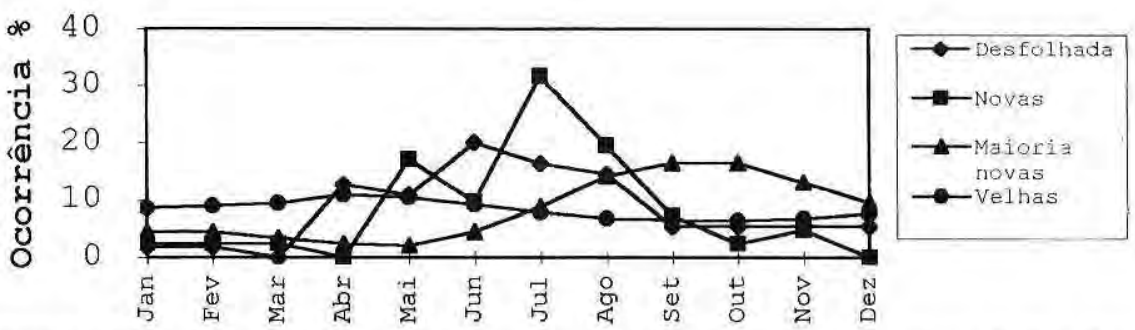

Figura 6. Floração (a), frutificação (b) e mudança foliar (c) de Couepia robusta Huber. Reserva Ducke, Manaus, AM, de 1970 a 1994.

\& Persaud, 1991; Franciscon, 1993). Cavalcante (1988), na região próxima a Belém (Pará), relatou que C. longipendula Pilger frutificou também na época chuvosa (entre janeiro e março). L. longistyla estava com frutos maduros entre julho e agosto, na transição para a estação seca e $L$. octandra em agosto e outubro, em plena estação seca, diferindo das outras três espécies. Este comportamento se deve ao fato de que em florestas tropicais muitas espécies frutificam todo o ano, mas existem flutuações no número de espécies, freqüentemente relacionadas a fatores ambientais (Snow, 1965; Opler et al. 1980). Longman \& Jenik (1974) relataram que várias espécies frutificam anualmente, bianualmente e outras de modo irregular, semelhante aos resultados de Araújo (1970) e Alencar et al. (1979). O clima sazonal também causa flutuações na ocorrência dos agentes polinizadores, 
dispersores, predadores e competidores, os quais podem afetar a fenologia das espécies (Lieberman, 1982).

O pico de folhas novas ocorreu no final da estação chuvosa (maio) para $L$. longistyla; $C$. longipendula em junho e $C$. robusta em julho, na transição para a estação seca; $L$. heteromorpha em agosto e $L$. octandra em setembro, na estação seca. Para todas as cinco espécies os picos de folhas novas antecederam aos picos da plena floração. Resultados similares foram relatados por Araújo (1970), Alencar et al. (1979), Magalhães \& Alencar (1979), Carvalho (1980), Miranda (1991) e Lima Junior (1992).

No presente estudo todas as espécies foram classificadas como perenifólias. Nas florestas tropicais sazonais sempre verdes a emissão de folhas freqüentemente ocorre na estação seca e os brotos emergem antes das chuvas; desta forma, o periodo seco seguido pelas primeiras chuvas pode ser um estímulo para o inicio do crescimento vegetativo ( Longman \& Jenik ,1974).

\section{Freqüência, regularidade e data da plena floração}

Em L. heteromorpha a plena floração ocorreu em 15 dos 25 anos observados, sendo considerada de freqüência anual a supra-anual. Quanto à Regularidade foi irregular (Fig. 7,Tab.1). $L$. longistyla apresentou plena floração em 14 anos deste estudo, dai considerar-se também como espécie de freqüência anual a supra-anual, e padrão irregular (Fig. 8,Tab.1). L. octandra apresentou botões florais em cinco anos deste estudo, mas foi observada com plena floração em apenas quatro anos (Fig. 9), com frequêencia supra-anual e padrão muito ir- regular (Tab.1). C. longipendula apresentou plena floração em 17 anos deste estudo, considerando-se a freqüência do tipo anual a supra-anual e padrão irregular (Fig. 10, Tab.1). C. robusta teve plena floração em 17 anos deste estudo, com exceção de 1974, apresentando freqüência anual a supra-anual, com padrão irregular (Fig.11, Tab.1).

As Chrysobalanaceae estudadas apresentaram freqüência e floração anual a supra-anual e padrão irregular, e somente $L$. octand $a$ apresentou o padrão supra-anual e muito irregular.

Segundo Janzen (1967), a floração na estação seca é vantajosa pois as condições do tempo favorecem a atividade de insetos polinizadores. Alencar et al. (1979) demostraram que houve uma tendência de encontrar um maior número de arvores iniciando a floração quando ocorreram menores valores de precipitação; relataram também que existem espécies que tiveram floração em intervalos de dois anos e floração irregular. Isto parece indicar que, além dos fatores climáticos, estão envolvidos fatores de interação com o biótopo e fatores fisiológicos. Borchert (1980) relatou que a continua repetição dos ciclos da floração, numa floresta seca da Costa Rica, depende das condições ambientais. Numa floresta seca da Costa Rica ocorreu baixo número de individuos com floração anual na época de chuvas, para a maioria das espécies, talvez pela menor atividade que têm os polinizadores nessa estação (Borchert, 1983), e que a variação sazonal e o conteúdo de água nas espécies florestais são aparentemente os principais determinantes da fenologia nessa região (Borchert, 1994). 


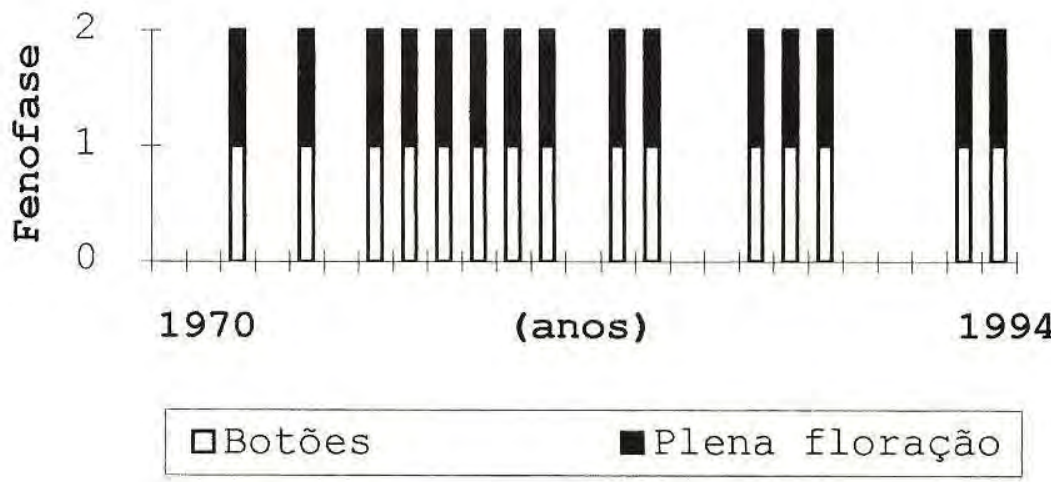

Figura 7. Freqüência da floração de Licania heteromorpha Bentham var. heteromorpha. Reserva Ducke, Manaus, AM, de 1970 a 1994.

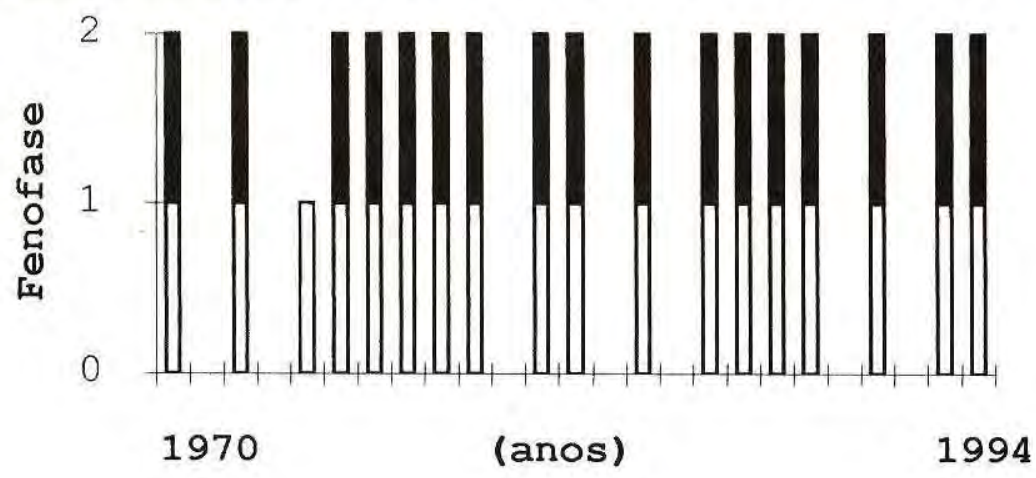

Figura 8. Freqüência da floração de Licania longistyla Fritsch. Reserva Ducke, Manaus, AM, de 1970 a 1994.

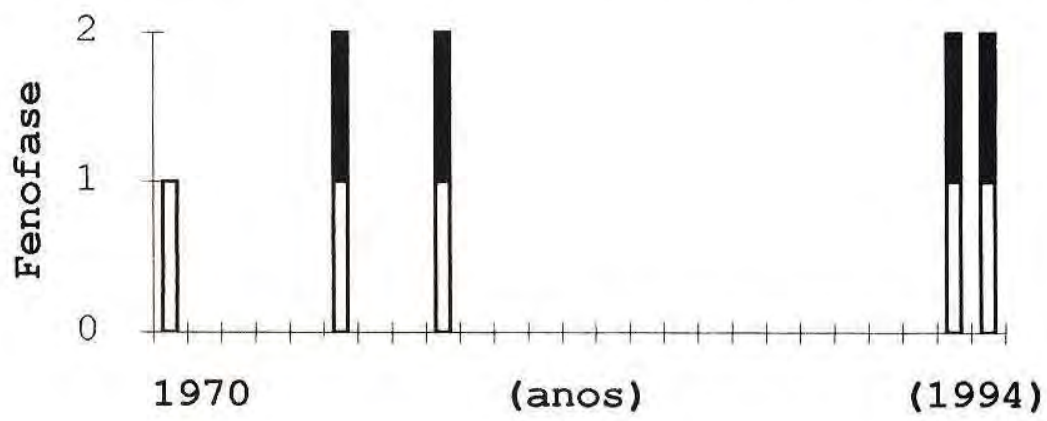

\section{口Botões $\quad$ Plena floração}

Figura 9. Freqüência da floração de Licania octandra var. pallida Prance. Reserva Ducke, Manaus, AM, de 1970 a 1994. 


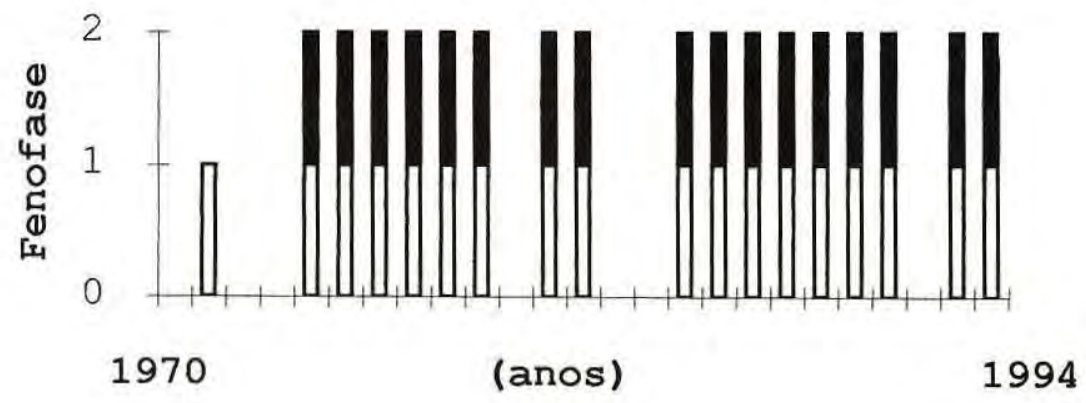

\section{aBotões $\quad$ Plena floração}

Figura 10. Freqüência da floração de Conepia longipendula Pilger. Reserva Ducke, Manaus, AM, de 1970 a 1994.

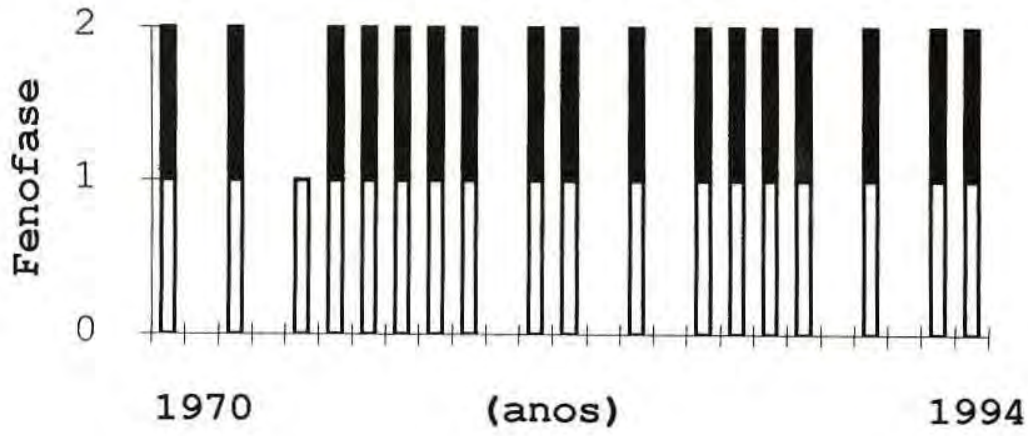

\section{aBotões $\quad$ Plena floração}

Figura 11. Freqüência da floração de Couepia robusta Huber. Reserva Ducke, Manaus, AM, de 1970 a 1994.

Tabela 1. Freqüência, regularidade e data da plena floração de cinco espécies de Chrysobalanaceae na Reserva Ducke, Manaus, AM, de 1970 a 1994.

\begin{tabular}{llll}
\hline Espécie & Freqüência & Regularidade & Data \\
\hline L. heteromorpha & Anual a supra-anual & Irregular & Nov.-Dez. (TC) \\
L. longistyla & Anual a supra-anual & Irregular & Mai.-Jul. ( TS) \\
L. octandra & Supra anual & Muito irregular & Mai.-Jul. (TS) \\
C. longipendula & Anual a supra-anual & Irregular & Set.-Nov.(ES e início da EC) \\
C. robusta & Anual a supra-anual & Irregular & Set.-Nov.(ES e início da EC)
\end{tabular}

TC = Transiçăo para a Estação chuvosa; $T S=$ Transiçăo para a Estação seca; $E S$ = Estação seca; EC = Estação chuvosa. 


\section{Duração média das fenofases}

A Duração média das fases de floração foi menor do que a das fases da frutificação para L. heteromorpha, $L$. longistyla, L. octandra e C. robusta (Tab.2), com valores de 4,5 e 5,$9 ; 4,8$ e 6,$0 ; 4,6$ e 5,$5 ; 4,9$ e 5,5 meses, respectivamente. Este resultado aproxima-se do relatado por Alencar et al. (1979) na Reserva Ducke. A duração da floração de $C$. longipendula foi prolongada ( $>5$ meses), e muito próxima da frutificação $(5,2$ e 4,9 meses) e as outras quatro espécies tiveram duração intermediária (1 a 5 meses).

\section{Sincronia}

Os Índicies de Sincronia para as espécies, entre os indivíduos e na população (Tab. 3), mostram que $L$. heteromorpha e L. longistyla apresentaram na plena floração e na fase de frutos maduros baixa sincronia entre os individuos. $\mathrm{Na}$ fase de folhas novas os valores foram ainda mais baixos, indicando que a sincronia foi minima. $L$. octandra, entretanto, apresentou alta sincronia na plena floração. A sincronia para frutos maduros foi entre média a alta, e na fase de folhas novas a sincronia foi baixa. $C$. longipendula mostrou na plena floração sincronia média a alta entre os indivíduos. $\mathrm{Na}$ fase de frutos maduros a sincronia foi média e na fase de folhas novas foi baixa. C. robusta apresentou baixa sincronia na floração entre indivíduos. Na fase de frutos maduros a sincronia variou de baixa a média e na fase de folhas novas a sincronia foi baixa.

A sincronia da população na plena floração foi alta para $L$. octandra $(0,79)$, média para $C$. longipendula $(0,56)$ e baixa para as outras espécies $(0,31)$; a fase de frutos novos também apresentou indices baixos de sincronia na população de $L$. heteromorpha, L. longistyla, $C$. longipendula e $C$. robusta $(<0,45)$ e valor entre médio e alto para $L$. octandra $(0,62)$; e a fase de folhas novas foi baixa ( $0,42)$ para todas as espécies. Pela análise não paramétrica de Kruskal-Wallis não existiu diferenças significativas entre espécies e entre indivíduos, para as fases de plena floração ( $\mathrm{Hc}=7,25 \mathrm{NS}$ ), frutos maduros $(\mathrm{Hc}=1,63 \mathrm{NS})$ e folhas novas $(\mathrm{Hc}=3,15 \mathrm{NS})$, embora L. octandra

Tabela 2. Duração média anual em meses das fenofases de cinco espécies de Chrysobalanaceae na Reserva Ducke, Manaus,AM, de 1970 a 1994.

\begin{tabular}{|c|c|c|c|c|c|c|c|c|c|c|c|}
\hline \multirow[t]{2}{*}{ Espécie } & \multirow[t]{2}{*}{ DM } & \multicolumn{3}{|c|}{ Floraçăo } & \multicolumn{3}{|c|}{ Frutificação } & \multicolumn{4}{|c|}{ Mudança foliar } \\
\hline & & 1 & 2 & 3 & 4 & 5 & 6 & 7 & 8 & 9 & 10 \\
\hline \multirow[t]{2}{*}{ L. heteromorpha } & $M$ & 1,0 & 1,6 & 1.9 & 2,0 & 2,1 & 1,7 & - & 1,1 & 3,4 & 9,3 \\
\hline & $s$ & 0,2 & 0,6 & 0,8 & 1,0 & 1,0 & 0,8 & - & 0,3 & 1,7 & 2,0 \\
\hline \multirow[t]{2}{*}{ L. longistyla } & $M$ & 1,3 & 1,6 & 2,0 & 1,8 & 2,2 & 2,0 & 2,6 & 1,3 & 3,2 & 10,2 \\
\hline & $\mathrm{s}$ & 0,4 & 0,6 & 0,7 & 0.7 & 1,2 & 0,9 & 1,8 & 0,5 & 1.5 & 2,0 \\
\hline \multirow[t]{2}{*}{ L. octandra } & $M$ & 1,9 & 1,4 & 1,3 & 2,1 & 1,8 & 1,6 & 1,0 & 1,4 & 2,9 & 9,4 \\
\hline & $\mathrm{s}$ & 1,0 & 0,5 & 0,5 & 0,8 & 0,7 & 0,7 & ND & 0,7 & 1,4 & 2,7 \\
\hline \multirow[t]{2}{*}{ C. longipendula } & M & 1,4 & 1,8 & 1,9 & 1,7 & 1,7 & 1,5 & 1,0 & 1,4 & 3,5 & 9.0 \\
\hline & $\mathrm{S}$ & 0,6 & 0.7 & 0,7 & 0,8 & 0,8 & 0,7 & ND & 0,8 & 1,8 & 2,1 \\
\hline \multirow[t]{2}{*}{ C. robusta } & $M$ & 1,4 & 1,7 & 1,8 & 1,9 & 2,0 & 1.6 & 1,6 & 1,1 & 4,1 & 8.3 \\
\hline & s & 0,5 & 0,6 & 0,8 & 1,0 & 1,0 & 0,5 & 1,2 & 0,3 & 1,8 & 2,7 \\
\hline
\end{tabular}

$\mathrm{DM}=$ duraçăo média anual $; \mathrm{M}=$ Média $; \mathrm{S}=$ desvio padrăo; $\mathrm{ND}=$ năo determinado 
Tabela 3. Sincronia média da piena floração (a), frutos maduros (b) e folhas novas (c) entre individuos e na população de cinco espécies de Chrysobalanaceae na Reserva Ducke, Manaus, AM, de 1970 a 1994.

a)

\begin{tabular}{lcccccc}
\hline Espécie & \multicolumn{7}{c}{ Individuos } & Populaçäo. \\
\hline & 1 & 2 & 3 & 4 & 5 & \\
L. heteromorpha & 0,30 & 0,21 & 0 & - & & 0,25 \\
L. longistyla & 0,11 & 0,50 & 0,30 & 0,46 & 0,16 & 0,31 \\
L. octandra & 1,00 & 1,00 & 0,67 & 0,67 & 0,63 & 0,79 \\
C. longipendula & 0,51 & 0,62 & 0,50 & 0,58 & 0,59 & 0,56 \\
C. robusta & 0,19 & 0,24 & 0,29 & 0,25 & 0,15 & 0,22 \\
\hline
\end{tabular}

b)

\begin{tabular}{|c|c|c|c|c|c|c|}
\hline Espécie & & & Individuos & & & População \\
\hline & 1 & 2 & 3 & 4 & 5 & \\
\hline L. heteromorpha & 0,21 & 0,15 & 0 & $\sim$ & - & 0,18 \\
\hline L. longistyla & 0,11 & 0,50 & 0,19 & 0,23 & 0,24 & 0,25 \\
\hline L. octandra & 0,63 & 0,63 & 0,94 & 0,40 & 0,50 & 0,62 \\
\hline C. longipendula & 0,33 & 0,50 & 0,44 & 0,40 & 0,46 & 0,43 \\
\hline C. robusta & 0,28 & 0,50 & 0,50 & 0,26 & 0,11 & 0,33 \\
\hline
\end{tabular}

c)

\begin{tabular}{lcccccc}
\hline Espécie & \multicolumn{3}{c}{ individuos } & População \\
\hline & 1 & 2 & 3 & 4 & 5 & 0,22 \\
L. heteromorpha & 0,27 & 0,23 & 0,16 & 0,08 & 0,05 & 0,10 \\
L. longistyla & 0,08 & 0,17 & 0,14 & 0,32 & 0,42 & 0,36 \\
L. octandra & 0,29 & 0,42 & 0,35 & 0,25 & 0,30 & 0,31 \\
C. longipendula & 0,25 & 0,39 & 0,37 & 0,33 & 0,35 & 0,27 \\
C. robusta & 0,10 & 0,25 & 0,31 & &
\end{tabular}

tenha apresentado valores de sincronia na plena floração superiores aos das outras espécies $\left(\mathrm{Hc}<\chi^{2}=9,49\right)$. Para as espécies estudadas não existem resultados de sincronia em floresta tropical na Amazônia Central, que permitam uma comparação e discussão dos mesmos.

\section{Análise dos componentes principais.}

A plena floração apresentou correlaçâo negativa com a precipitação ( $\mathrm{r}$ $=-0,34)$ e umidade relativa $(\mathrm{r}=-0,34)$ e correlação positiva com a evaporação $(r=$ $0,31)$, insolação $(r=0,29)$ e temperatura máxima $(r=0,26)$ (Tab. 4). Os frutos maduros mostraram correlação positiva com a precipitação $(r=0,27)$ e correlação negativa com a temperatura mínima $(\mathrm{r}=$ $0,35)$ e com a insolação $(r=-0,27)$. As folhas novas apresentaram correlação positiva com a insolação $(r=0,61)$, temperatura máxima $(r=0,36)$ e com a temperatura média $(r=0,33)$, mas, a correlaçào foi negativa com a precipitação $(r=-0,57)$, evaporação $(r$ $=-0,51)$, umidade relativa $(r=-0,41) \mathrm{e}$ com a temperatura mínima $(\mathrm{r}=-0,48)$.

Alencar (1994) relatou resultados semelhantes para cinco espécies de 
Tabela 4. Valores de correlação linear, segundo a Análise dos Componentes Principais, entre as fases de plena floração $\left(\mathrm{F}_{2}\right)$, frutos maduros $\left(\mathrm{F}_{5}\right)$ e folhas novas $\left(\mathrm{F}_{8}\right)$ de cinco espécies de Chrysobalanaceae e as variáveis meteorológicas na Reserva Ducke, Manaus, AM, de 1970 a 1994.

\begin{tabular}{lcccccccccc}
\hline Variảvel & $F_{2}$ & $F_{5}$ & $F_{8}$ & PP & TM & TME & TMI & INS & URE & EVP \\
\hline$F_{2}$ & 1,00 & & & & & & & & & \\
$F_{5}$ & $-0,37$ & 1,00 & & & & & & & & \\
$F_{8}$ & $-0,13$ & $-0,14$ & 1,00 & & & & & & & \\
PP & $-0,34$ & 0,27 & $-0,57$ & 1,00 & & & & & & \\
TM & 0,26 & $-0,02$ & 0,36 & $-0,64$ & 1,00 & & & & & \\
TME & 0,25 & 0,02 & 0,33 & $-0,58$ & 0,97 & 1,00 & & & & \\
TMI & $-0,14$ & $-0,35$ & $-0,48$ & 0,72 & $-0,03$ & 0,10 & 1,00 & & & \\
INS & 0,29 & $-0,27$ & 0,61 & $-0,93$ & 0,69 & 0,61 & $-0,69$ & 1,00 & & \\
URE & $-0,34$ & 0,08 & $-0,41$ & 0,82 & 0,80 & $-0,78$ & 0,32 & $-0,77$ & 1,00 & \\
EVP & 0,31 & $-0,16$ & $-0,51$ & $-0,88$ & 0,86 & 0,78 & $-0,46$ & 0,92 & $-0,93$ & 1,00 \\
\hline
\end{tabular}

$\mathrm{N}=12$ meses $\times 5$ espécies $=60$

G.L. $=58 ; r \cong 0,26$ a $5 \%$. Valores em negrito säo significativos.

PP (precipitação) TM (Temperatura máxima); TME (Temperatura média); TMI (Temperatura mínima); Insolação (INS); URE (Umidade relativa); EVP (Evaporação).

Sapotaceae na Reserva Ducke. Alencar et al. (1979) determinaram também que para o inicio da floração e frutificação a correlação com a precipitação e umidade relativa foi linear negativa; a correlação entre a frutificação e a temperatura máxima foi linear positiva, porém não significativa com a floração.

Pela representação plana das variáveis nos eixos 1 e 2 (Fig. 12) observase que $\mathrm{F}_{2}$ (plena floração), $\mathrm{F}_{8}$ (folhas novas), INS (insolação) e EVP (evaporação) estão associadas (Grupo 1); vê-se também que do Grupo 2 fazem parte as variáveis PP (precipitação), $\mathrm{F}_{5}$ (frutos maduros) e TMIN (temperatura mínima), as quais estão em oposição às variáveis do grupo 1; observa-se ainda que as variáveis URE (umidade relativa), TM (temperatura máxima) e TME (temperatura média) estão mal representadas, afastadas dos grupos 1 e 2. Isto mostra que as fases de plena floração, folhas novas e as variáveis insolação e evaporação estão ligadas à estação seca, enquanto que a fase de frutos maduros está correlacionada com a precipitação e a temperatura mínima, que caracterizam a estação chuvosa.

\section{CONCLUSÕES}

L. longistyla e L. octandra mostraram picos de plena floração na transição para a estação seca; $C$. longipendula e $C$. robusta na estação seca e $L$. heteromorpha na estação chuvosa. Os picos de produção de frutos maduros de $\mathrm{L}$. heteromorpha, C. longipendula e C. robusta ocorreram na estação chuvosa; $L$. longistyla ocorreu na transição para a estação seca e $L$. octandra na estação seca.

L. heteromorpha, L. longistyla, $C$. longipendula e $C$. robusta tiveram 


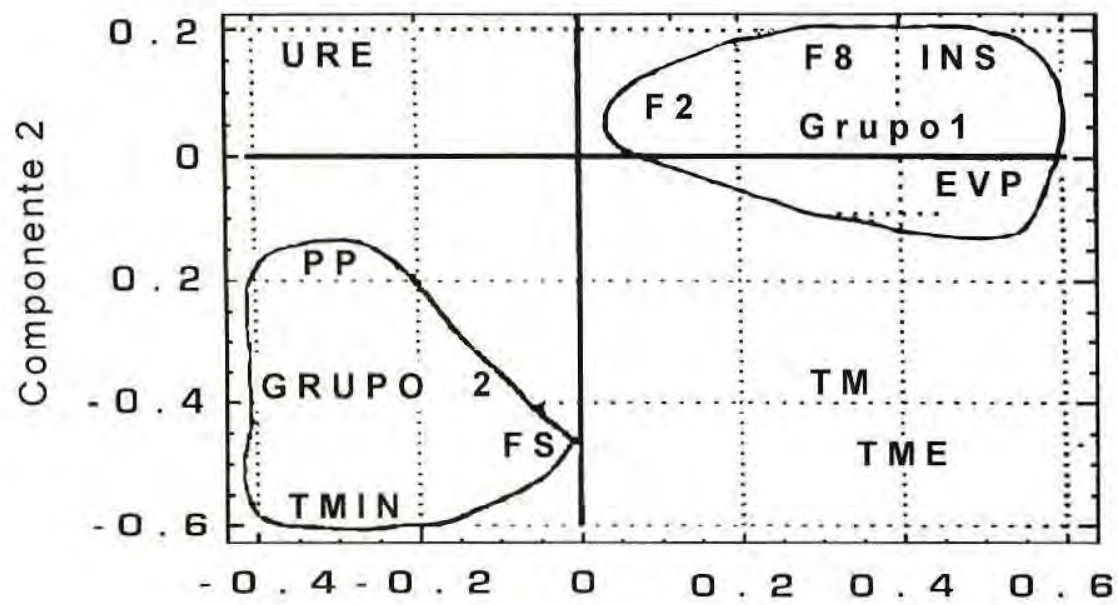

Componente 1

Figura 12. Representaçào plana das relaçòes entre variáveis fenológicas e meteorológicas nos primeiros dois componentes principais no conjunto de cinco espécies de Chrysobalanaceae observadas de 1970 a 1994 na Reserva Florestal Ducke, Manaus, AM. Plena floraçào $\left(\mathrm{F}_{2}\right)$, frutos maduros $\left(\mathrm{F}_{5}\right)$, folhas novas $\left(\mathrm{F}_{\mathrm{s}}\right)$. TM (temperatura máxima);TME (temperatura média);TMIN (temperatura mínima);URE (umidade relativa); INS (insolação); EVP (evaporação); PP (precipitação).

freqüência anual a supra-anual e padrão irregular na floração; somente $L$. octandra apresentou freqüência supra-anual e padrão muito irregular. Todas as cinco espécies foram consideradas perenifólias.

A análise dos componentes principais, para as espécies em conjunto, mostrou que a plena floração $\left(\mathrm{F}_{2}\right)$ teve correlação linear negativa com a precipitação e umidade relativa, e positiva com a insolação, evaporação e temperatura máxima; a fase de frutos maduros $\left(\mathrm{F}_{5}\right)$ apresentou correlação positiva com a precipitação e negativa com a temperatura minima e insolação; a fase de folhas novas $\left(\mathrm{F}_{8}\right)$ teve correlação semelhante à da plena floração. A representaçâo plana das relações entre as variáveis fenológicas e meteorológicas mostrou que as fases de plena floração e folhas novas estão ligadas à insolação e evaporação, fazendo parte de um grupo (estação seca) que se opõe ao grupo onde estão as variáveis frutos maduros, precipitação e temperatura minima (estação chuvosa).

O comportamento fenológico destas espécies de Chrysobalanaceae é similar aos padrões da maioria das espécies arbóreas já estudadas na Amazônia Central.

\section{Bibliografia citada}

Alencar, J.C. 1988. Estudos silviculturais de uma população natural de Copaifera multijuga Hayne Leguminosae, na Amazônia Central. IV. Interpretação de dados fenológicos em relação a elementos climáticos. Acta Amazonica, 18(34):199-209.

1990. Interpretação fenológica de espécies lenhosas de campina na Reserva Biológica de Campina do Inpa ao norte de Manaus. Acta Amazonica, 20 (único):145-183.

.... 1991. Estudos fenológicos de espécies florestais arbórcas e de palmeiras nativas da Amazónia. In: Val, A.L.; Figliuolo, R.; Feldberg, E. (Eds.). Bases Cientificas para Estratégias de Preservação e Desenvolvimento da Amazónia: Fatos e 
Perspectivas. Vol. I. INPA, Manaus. p. 215-220.

1994. Fenologia de cinco espécies arbóreas tropicais de Sapotaceae correlacionada a variáveis climáticas na Reserva Ducke, Manaus, AM. Acta Amazonica, 24(3/4):161-182.

Alencar, J.C.; Araújo, V.C. 1980. Comportamento de espécies florestais amazônicas quanto à luminosidade. Acta Amazonica, 10(3):435-444.

Alencar, J.C.; Almeida, R.A.; Fernandes, N.P. 1979. Fenologia de espécies florestais em floresta tropical úmida de terra firme na Amazônia Central. Acta Amazonica, 9(1):163-198.

Alvim, P. de T. 1962. Energia solar y producción agricola. Revista Agronomia, 29(2):1-9.

Alvim, P. de T. 1964. Periodicidade do crescimento de árvores em climas tropicais. Anais do XV Congreso da Sociedade Botânica do Brasil. Porto Alegre, p. 405-422.

Araújo, V.C. 1970. Fenologia de essências florestais amazônicas I. Boletim do INPA, (4):1-25.

Arostegui, A.; Diaz, M. 1992. Propagación de espécies forestales nativas promisorias en Jenaro Herrera. Instituto de Investigaciones de la Amazonia Peruana (IIAP), Iquitos, Perú. 119 p.

Augspurger, C.K. 1983. Phenology, flowering synchrony and fruit set of six Neotropical shrubs. Biotropica, 15(4):257-267.

Borchert, R. 1980. Phenology and ecophysiology of tropical trees: Erythrina poeppigiana O.F. Cook. Ecology, 61(5):1065-1074.

Borchert, R. 1983. Phenology and control of flowering in tropical trees. Biotropica, 15:81-89.

Borchert, R. 1994. Soil and stem water storage determine phenology and distribution of tropical dry forest trees. Ecology, 75(5):1437-1449.

Bouroche, J.-M.; Saporta, G. 1980. Que saisje? L'analyse des données. $3^{\text {a }}$ édition. Presses Universitaires de France. Paris.127p.

Campos, H. de. 1979, Estatistica Experimen- tal Não-Paramétrica, $3^{\text {a }}$ ed. Universidade de São Paulo, Piracicaba. 343 p.

Callegari-Jacques, S.M. 1991. Análise Fatorial de Correspondência: Aplicações em Genética. Universidade Federal do Rio Grande do Sul, Porto Alegre. 28 p.

Carvalho, J.O.P. 1980. Fenologia de espécies florestais de potencial econômico que ocorrem na floresta do Tapajós. EMBRAPA, CPATU. Boletim de Pesquisa, 20:1-15.

Cavalcante, P.B. 1988. Frutas comestiveis da Amazônia, $4^{a} \mathrm{ed}$. Museu Paraense Emílio Goeldi, Companhia Souza Cruz Indústria e Comércio, Belém. 279 p.

Daubenmire, R. 1972. Phenology and other characteristics of tropical semi-deciduous forest in North-Western Costa Rica. Journal of Ecology, 60(1):147-170.

Falcão, M. de A.; Lleras, E.; Kerr, W.E. 1981. Aspectos fenológicos, ecológicos e de produtividade do Pajurá (Couepia bracteosa Bentham) (Chrysobalanaceae). Acta Amazonica, 11(3):473-482.

Franciscon, C.H. 1993. Distribuiçào geográfica e estado atual do conhecimento de 10 espécies de extrativismo, ocorrentes na Reserva Florestal Ducke, Manaus, AM (Amazônia Central). Dissertação de Mestrado, INPA/ FUA, Manaus. 94p.

Jackson, M.T. 1966. Effects of microclimate on spring flowering phenology. Ecology, 47:407-415.

Janzen, D.H. 1967. Synchronization of sexual reproduction of trees within the dry season in Central America. Evolution, 21(3):620-637.

Lieberman, D. 1982. Seasonality and phenology in a dry forest in Ghana. Journal of Ecology, 70: 791-806.

Lima Junior, M.J.V. 1992. Fenologia de cinco espécies de Lecythidaceae da Reserva Florestal Ducke, Manaus-AM. Dissertação de Mestrado, INPA/FUA, Manaus. 72 p.

Longman, K.A.; Jenik, J. 1974. Tropical Forest and its environment. Tropical Ecology Series. London and New York. 196 p.

Magalhães, L.M.S.; Alencar, J.C. 1979. Fenologia do Pau-rosa (Aniba duckei Kostermans), Lauraceae, em Floresta 
Primária na Amazônia Central. Acta Amazonica, 9(2):227-232.

Miranda, I.S. 1991. Estrutura e fenologia de uma comunidade arbórea da savana Amazónica de Alter-do-chão, Pará. Tese de Mestado, INPA/FUA, Manaus.129 p.

Mori, A.S.; Prance, G.T. 1979. Lecythidaceae. Part.I. Flora Neotropica, 21:1-179.

Newstrom, L.E.; Frankie, G.W.; Baker, H.G. 1994a. A new classification for plant phenology based on flowering patterns in lowland tropical rain forest trees at La Selva, Costa Rica. Biotropica, 26(2):141-159.

Newstrom, L.E.; Frankie, G.W.; Baker, H.G; Colwell, R.K. 1994b. Diversity of longterm flowering patterns. In: Hespenheide, H.A.; Hartshorn, G.S. (Eds.) La Selva. Ecology and Natural History of a Neotropical Rain Forest. The University of Chicago Press, Chicago. p.142-160.

Opler, P.A.; Frankie, G.W.; Baker, H.G. 1980. Comparative phenology studies of treelet and shrub species in tropical wet and dry forest in the lowlands of Costa Rica. Journal of Ecology, 68;167-188.

Philippeau, G. 1992. Comment interpréter les résultats d'une analyse en composantes principales? Collection ITCF-ISBN, Paris. 63p.

Primack, R.B. 1980. Variation in the phenology of natural populations of montane shrubs in New Zealand. Journal of Ecology, 68:849-862.

Ranzani, G. 1979. Recursos pedológicos da Amazônia. Acta Amazonica, 9(4):23-35.
Reich, P.B.; Borchert, R. 1984. Water stress and phenology in a tropical dry forest in the lowlands of Costa Rica. Journal of Ecology, 72:61-74.

Ribeiro, M.N.G. 1976. Aspectos climatológicos de Manaus. Acta Amazonica, 6(2):229-233.

Rodriguez, J.C. 1995. Aspectos fitossociológicos das comunidades vegetais de uma toposseqüencia da Reserva Florestal Ducke do INPA, Manaus-AM. Tese de Doutorado, INPA/FUA, Manaus. 284 p.

Romero, R.; Romero, M. 1983. Proyecto de Investigación en Utilización y Manejo de Bosques.. Red de Investigación Agraria para la Amazonia (REDINAA). Lima. 180 p.

Sabatier, D. 1985. Saisonalité et déterminisme du pic de fructification en forèt Guyanaise. Revue Ecologie, 40:289-320.

Smythe, N. 1970. Relationships between fruiting seasons and seed dispersal methods in a neotropical forest. The American Naturalist, 104:25-35.

Snow, D.W. 1965. A possible selective factor in the evolution of fruiting seasons in tropical forest. Oikos, 15:274-281.

Steege, H.; Persaud, C.A. 1991. The phenology of Guyanese timber species: a compilation of a century of observations. Vegetativo, 95:177198.

Umaña, C.L.A.; Alencar, J.C. 1993. Comportamento fenológico da Sucupira-Preta (Diplotropis purpurea Rich. Amsh, var. coriacea Amsh.) na Reserva Florestal Ducke. Acta Amazonica, 23(1):199-211. 